\title{
PELATIHAN KETRAMPILAN MENDENGARKAN EMPATIK AKTIF UNTUK MENINGKATKAN KEDEKATAN GURU DAN ANAK
}

\author{
Ika Setya Mahanani ${ }^{1}$ \\ Sri Redatin Retno Pudjiati \\ Patricia
}

\author{
Fakultas Psikologi, Universitas Indonesia, Depok
}

\begin{abstract}
Closeness in teachers-child relationship in early childhood education has a positive impact in increasing the involvement of children with school, improve academic achievement, prosocial behavior and reduce child problem behavior. This study aims to improve closeness in teacher-child relationship in early childhood education through active empathic listening skills training. Participants are four early childhood education teachers. Teacher-child relationships are measured based on teachers' perceptions of their relationship with children. Teachers fill the questionnaire by her perception of her relationship with 5 children. This research uses quasi experimental method with one group pretest-posttest design. The results of statistical data processing showed a very significant change in the increase of closeness level of teacher-child relationship between pretest and post test $1(z=-3.560, p=0.000<0,01)$, and post test 1 with post test $2(z=-3.220, p=0.001<0,05)$. Active empathic listening skill showed significant improvement between pre test and post test $1(z=-1.826, p=0.34<0,05)$ and no significant improvement between post test 1 and post test $2(z=-1.342, p=0.090>0,05)$.
\end{abstract}

Keywords: active empathic listening skill, closeness, teacher-child relationships, early childhood education teachers, early childhood

\begin{abstract}
ABSTRAK: Closeness hubungan guru dan anak di PAUD memberikan dampak positif dalam meningkatkan keterlibatan anak dengan sekolah, peningkatan prestasi akademis, perilaku prososial serta mengurangi perilaku bermasalah anak. Penelitian ini bertujuan untuk meningkatkan closeness dalam hubungan guru dan anak di PAUD melalui pelatihan active empathic listening skill. Subjek penelitian adalah empat orang guru PAUD. Hubungan guru diukur berdasarkan persepsi guru terhadap hubungannya dengan anak. Masing-masing guru akan dilihat persepsi hubungannya dengan lima anak didik. Penelitian ini menggunakan metode quasi eksperimental dengan desain penelitian one group pretest-posttest design. Hasil pengolahan data statistik menunjukkan adanya perubahan sangat signifikan pada kenaikan tingkat closeness hubungan guru dan anak antara pre test dan post test $1(\mathrm{z}=-3.560, \mathrm{p}=0.000<0,01)$, serta post test 1 dengan post test $2(\mathrm{z}=-3.220, \mathrm{p}=0.001<0,05)$. Sedangkan skor active empathic listening skill menunjukkan adanya peningkatan signifikan antara pre test dan post test $1(\mathrm{z}=$ $1.826, \mathrm{p}=0.34<0,05$ ) dan tidak ada peningkatan signifikan antara post test 1 dengan post test 2 $(\mathrm{z}=-1.342, \mathrm{p}=0.090>0,05)$.
\end{abstract}

Kata kunci: Ketrampilan Mendengarkan Empatik Aktif, closeness hubungan guru dan anak, guru PAUD, anak usia dini

\footnotetext{
${ }^{1}$ Korespondensi mengenai artikel ini dapat dilakukan melalui: ika.setya51@ui.ac.id
} 
Masa peka setiap anak berbeda dan bersifat individual seiring dengan laju pertumbuhan dan perkembangan anak sesuai dengan kebutuhan masing-masing anak. Figur lekat anak perlu memberikan stimulasi yang dibutuhkan anak sesuai dengan kebutuhan perkembangannya. Lembaga pendidikan untuk anak usia dini (PAUD), termasuk guru, merupakan salah satu pihak selain orang tua yang dapat membantu memaksimalkan pemberian stimulasi yang dibutuhkan oleh anak usia dini (Santrock, 2011).

Guru berperan sangat signifikan mengoptimalkan potensi anak agar dapat teraktualisasi (Slavin, 2011). Guru mengorganisasi/mengatur lingkungan belajar anak serta merencanakan berbagai pengalaman supaya dapat meningkatkan rasa ingin tahu dan semangat anak untuk belajar sehingga perkembangan kognitifnya meningkat (Lynch \& Warner, 2013). Berns (2013) menegaskan bahwa guru dapat membantu untuk menumbuhkembangkan berbagai keterampilan dan perilaku, serta memberikan motivasi bagi anak agar sukses belajar.

Supaya perkembangan dan pertumbuhan anak dapat tercapai secara optimal, guru perlu menjalin hubungan baik dengan anak agar nilai-nilai yang disampaikan guru dapat tertransfer dan terinternalisasi dalam diri anak. Hubungan guru dan anak yang positif yang dibutuhkan oleh anak adalah hubungan yang memiliki kedekatan atau closeness yang ditandai dengan adanya keterbukaan, perhatian dan kehangatan antara guru dan anak (Rudasill, Reio, Stipanovic, \& Taylor, 2010). Guru dan anak harus berada dalam hubungan yang menggambarkan closeness (kedekatan) yang ditandai terdapat kepercayaan dan komunikasi terbuka antara guru dan anak (Zee, de Jong, \& Komen, 2016).

Closeness adalah salah satu dari tiga dimensi yang terdapat dalam hubungan antara guru dengan anak, selain conflict, dan dependency (Koomen, Verschueren, van Schooten, Jak, \& Pianta, 2010). Closeness atau kedekatan ditunjukkan dengan adanya kehangatan dalam hubungan, perasaan aman dan adanya komunikasi terbuka di antara guru dan anak di lingkungan sekolah. Ikatan afeksi yang hangat terhadap orang yang signifikan di kelas dapat memberikan efek positif terhadap sekolah.

Pentingnya guru dan anak memiliki hubungan kedekatan terlihat dari hasil penelitian yang menunjukkan bahwa anak yang memiliki hubungan kedekatan dengan guru memiliki perilaku prososial, terlepas dari jenis temperamen yang dimiliki anak (Myers \& Morris, 2009) dan memiliki keterampilan sosial yang baik (Demirkaya \& Bakkaloglu, 2015). Hubungan yang memiliki kedekatan (closeness) antara guru dan anak jug dapat memberikan dukungan, dorongan, dan bimbingan yang diperlukan anak agar dapat berkembang di kelas (Commodari, 2013), mengurangi terjadinya perilaku bermasalah pada anak (Zee, de Jong, \& Koomen, 2016), menunjukkan perilaku yang baik di sekolah dan senang terlibat dalam kegiatan di sekolah (Birch \& Ladd, 1997).

Pianta, Downer, Jason, dan Hamre (2016) menyatakan bahwa dalam hubungan guru dan siswa yang positif terlihat dalam bentuk sensitivitas guru terhadap kebutuhan setiap anak, dukungan terhadap perilaku positif, dan stimulasi bahasa serta perkembangan kognitif. Anak dapat belajar lebih baik ketika guru mampu meningkatkan pemahaman konsepual, memberikan feedback yang mendukung berbagai 
kemampuan anak dan terlibat penuh ketika berbicara dengan anak. Oleh karena itu dapat disimpulkan bahwa hubungan yang baik dan positif antara guru dan anak memerlukan komunikasi yang baik.

Berkaitan dengan hal tersebut, Pianta (2001) menyatakan bahwa karakter dan perilaku guru dan anak secara timbal balik dapat saling mempengaruhi. Oleh karena itu, guru perlu memiliki pengetahuan, sikap, dan keterampilan berkomunikasi dalam membimbing anak. Hal tersebut diperlukan agar guru mampu menjalin hubungan yang baik dengan anak, sehingga nilai-nilai yang disampaikan guru dapat terinternalisasi dalam diri mereka.

Standar Nasional Pendidikan Anak Usia Dini menyatakan bahwa guru perlu memiliki kemampuan mengetahui serta menjalankan strategi berkomunikasi yang efektif, empatik, dan santun dengan anak usia dini (Menteri Pendidikan dan Kebudayaan Republik Indonesia, 2014a). Fowler, Banks, Anhalt, Hinrichs, dan Kalis (2008) juga menambahkan bahwa guru merupakan salah satu figur lekat bagi anak yang berperan memberikan dukungan, memberikan kepercayaan pada anak, memberikan dorongan, perlindungan dan melakukan komunikasi secara terbuka sebagai bentuk penerimaan terhadap kebutuhan sosial emosional maupun akademik anak Oleh sebab itu, hubungan antara guru dan anak menjadi krusial, karena dapat mempengaruhi perkembangan anak. Harapan tersebut bertolak belakang dengan hasil studi preliminari yang dilakukan peneliti pada tiga PAUD di kecamatan J, yang menemukan bahwa masalah yang sering muncul bukan masalah akademis anak, melainkan masalah nonakademis. Beberapa guru banyak mengeluhkan sulitnya mengarahkan dan mendisiplinkan anak-anak di sekolah, juga sulit membuat anak-anak mendengarkan yang disampaikan oleh guru. Guru akhirnya banyak menggunakan komunikasi verbal yang negatif, misalnya dengan marah dan ancaman. Selain itu, para guru tersebut juga tidak pernah mendapatkan pelatihan pembelajaran berkaitan dengan cara berkomunikasi yang efektif, khususnya cara mendengarkan anak dengan baik supaya lebih memahami dan lebih merasa dekat dengan anak. Berdasarkan temuan tersebut, guru PAUD perlu mendapatkan ketrampilan mendengarkan yang mampu menjalin kedekatan hubungan, sehingga anak-anak lebih mau mengikuti instruksi dan arahan dari guru.

\section{Keterampilan Mendengarkan}

Dasar suatu hubungan adalah komunikasi. Semakin baik keterampilan komunikasi seseorang, maka kemungkinan terjalin hubungan positif dengan orang lain juga akan semakin tinggi (Kourmousi, Amanaki, Tzavara, \& Koutras, 2017). Hal ini selaras dengan pandangan Ashokan (2014) yang menyatakan bahwa komunikasi merupakan hal yang fundamental dalam perkembangan anak. Komunikasi yang baik antara anak dan guru juga dapat membantu anak untuk mengembangkan kemampuan kognitif, sosial, emosional dan moral (Rahiem, Abdullah, \& Rahim, 2012). Cara seseorang berkomunikasi dapat menentukan respons yang diterima. Cara guru dalam melakukan komunikasi dapat mendorong motivasi, memodifikasi sikap, memacu kreativitas, dan merangsang pemikiran anak. Sebaliknya, komunikasi yang kurang baik akan menimbulkan salah paham, munculnya kesan kurang baik, pesan akan terdistorsi dan sulit dipahami oleh anak, juga proses belajar bisa menjadi 
terhambat (Fauzi, 2011). Hasil penelitian Duta, Panisoara dan Panisoara (2015) membenarkan bahwa guru dengan kemampuan komunikasi yang baik dapat mengembangkan proses belajar mengajar yang lebih baik dan menyenangkan bagi anak.

Hubungan guru dan anak dapat terjalin dengan baik melalui komunikasi yang baik. Bagian utama dari komunikasi salah satunya adalah keterampilan mendengarkan (listening skill), karena ini mendasari fungsi penting komunikasi (Gearhart \& Bodie, 2011). Listening skill merupakan keterampilan yang sangat mendasar dalam komunikasi untuk membuat dan menjaga suatu hubungan yang baik (Santrock, 2011). Guru perlu memiliki keterampilan mendengarkan, karena memiliki peran yang sangat penting dalam komunikasi antara guru dan anak (Kourmousi, Amanaki, Tzavara, \& Koutras, 2017). Guru PAUD perlu memiliki keterampilan mendengarkan karena anak masih dalam proses berkembang, belum bisa secara sempurna mengungkapkan diri dan kebutuhannya, kosakata belum lengkap sehingga guru perlu peka dalam melihat dan mendengarkan anak-anak. Perilaku mendengarkan menunjukkan penghargaan terhadap orang lain, dan dapat menjaga serta meningkatkan hubungan interpersonal yang positif (Lloyd, Boer, \& Voelpel, 2015). Oleh karena itu, guru perlu memiliki keterampilan mendengarkan secara aktif dan menunjukkan penghargaan terhadap anak.

Keterampilan mendengarkan secara aktif, biasa disebut dengan active listening, adalah perilaku mendengarkan yang dilakukan dengan beberapa proses, seperti melakukan parafrase, menyampaikan pertanyaan-pertanyaan yang sesuai dengan pembicaraan, dan menampilkan perilaku non-verbal tertentu yang menunjukkan sebagai pendengar yang baik (Weger, Bell, Minei, \& Robinson, 2014). Perilaku yang ditunjukkan sebagai pendengar yang baik yang menerapkan active listening selain menjaga kontak mata, yaitu menunjukkan gerakan non-verbal yang mendukung orang yang sedang berbicara dengannya, seperti mengangguk atau tersenyum, dan tidak menginterupsinya (Kourmousi, Amanaki, Tzavara, \& Koutras, 2017). Seseorang yang menerapkan active listening juga menunjukkan atensi dalam perilaku verbal, seperti melakukan parafrase, merefleksikan perasaan, memeriksa asumsi, dan menyampaikan pertanyaan-pertanyaan (Bodie, Vickery, Cannava \& Jones, 2013). Penerapan keterampilan active listening dapat membangun hubungan berdasarkan kepercayaan, ketulusan dan minat (interest).

\section{Empati}

Mendengarkan secara aktif saja bagi guru PAUD tidak cukup, karena anak usia dini perlu dipahami berdasarkan kebutuhan dan keunikannya masing-masing. Guru juga perlu mendengarkan dengan penuh empati. Anak bersifat unik, berbeda satu sama lain. Mereka memiliki minat, bawaan, kapabilitas dan latar belakang kehidupan masingmasing. Meskipun terdapat pola urutan umum dalam perkembangan anak yang dapat diprediksi, pola perkembangan dan belajarnya tetap memiliki perbedaan satu sama lain (Tim Pengembang Ilmu Pendidikan FIP UPI, 2007). Hasil penelitian Peck, Maude dan Brotherson (2015), menunjukkan bahwa empati membuat guru dapat memahami, dapat merasakan, membuat mudah berkomunikasi dengan anak dan merespons kebutuhan anak. 
Anak usia PAUD yang berada dalam masa perkembangan membutuhkan dukungan emosi dalam bentuk empati dari lingkungan sekitar, terutama orang tua dan guru. Oleh karena itu, guru perlu memiliki keterampilan mendengarkan yang baik, secara aktif dan penuh empati. Lebih lanjut, berkomunikasi secara empati dan efektif juga merupakan salah satu indikator kompetensi sosial dalam standar pendidik dan tenaga kependidikan PAUD menurut Badan Standar Nasional Pendidikan Tahun 2009. Hal ini juga dipertegas dalam Permendikbud Nomor 137 Tahun 2014 Tentang Standar Nasional Pendidikan Anak Usia Dini, disebutkan pada kompetensi inti yang pertama, Kompetensi Pedagogik, salah satu kompetensinya adalah berkomunikasi secara efektif, empatik, dan santun; di mana guru mampu memilih berbagai strategi berkomunikasi yang efektif, empatik dan santun dengan anak usia dini. Berdasarkan penjelasan tersebut, maka guru PAUD perlu memiliki kemampuan empati, khususnya dalam berkomunikasi dengan anak, sehingga terbina hubungan yang baik dengan anak.

Allison, Baron-Cohen, Wheelwright, Stone, dan Muncer (2011) menyatakan bahwa empati membantu individu untuk memahami orang lain, baik perilaku maupun perasaannya, bahkan memprediksi perilaku berikutnya dan memberikan respons dengan cara yang tepat. Peck, Maude dan Brotherson (2015) juga menegaskan bahwa para guru yang menunjukkan empati yang baik terhadap anak dapat membangun fondasi stabilitas emosi dan rasa aman yang membentuk hubungan yang baik dengan anak. Dengan mendengarkan secara empati, guru menunjukkan dukungan emosi terhadap anak.
Dalam hubungan yang menunjukkan kedekatan, perilaku mendengarkan (listening) memperlihatkan perilaku afeksi, dukungan, empati, dan pengertian (Notarius dan Herrick dalam Bodie, 2011). Jadi, ketika seseorang mendengarkan orang lain maka seseorang memberikan perhatian penuh dan menunjukkan perilaku empati.

\section{Active Empathic Listening Skill}

Drollinger, Comer, dan Warrington (2006) menyatakan bahwa keterampilan mendengarkan yang paling efektif adalah yang mengkombinasikan empati dengan teknik active listening. Keterampilan yang perlu dimiliki oleh guru PAUD ini disebut sebagai active empathic listening skill, yaitu keterampilan mendengarkan yang terdapat pelibatan secara aktif dan emosi seorang pendengar selama melakukan interaksi, dimana pelibatan dilakukan secara sadar dan juga disadari oleh pihak yang sedang berbicara (Gearhart \& Bodie, 2011).

Active empathic listening skill adalah keterampilan mendengarkan yang terdapat pelibatan secara aktif dan emosi oleh pendengar selama melakukan interaksi, dan pelibatan tersebut dilakukan secara sadar oleh pendengar juga disadari oleh pihak yang sedang berbicara (Bodie, 2011). Active empathic listening merupakan suatu tindakan dalam mendengarkan yang secara bertahap terdiri dari sensing (menyadari dan fokus pada sebuah pesan), processing (memproses/menafsirkan pesan itu), dan responding (merespons dengan tepat) (Pence \& Vickery, 2012).

Kourmousi, Amanaki, Tzavara, dan Koutras (2017) juga menyebutkan bahwa active empathic listening skill merupakan suatu ketrampilan mendengarkan yang dilakukan dengan empatik, mencakup teknik-teknik seperti menjaga kontak mata, 
tidak menginterupsi pembicara, membuat komentar yang memberi semangat atau isyarat non-verbal, merumuskan pertanyaan yang tepat, melakukan parafrase, dan ringkasan untuk menunjukkan pemahaman tentang hal-hal yang dikatakan pembicara. Jadi, active empathic listening skill merupakan keterampilan mendengarkan yang dilakukan secara aktif dan penuh empati oleh pendengar dengan memberikan respons baik secara verbal maupun non verbal dan disadari oleh pendengar maupun yang berbicara.

Terdapat tiga tahapan dalam melakukan active empathic listening (Bodie, 2011), yaitu sensing, di mana pendengar terlibat secara aktif dengan menyiapkan diri untuk menerima setiap kata. Pendengar memberikan perhatian seluruhnya (attending), mengetahui komponen bahasa yang digunakan (vocabulary) dan menangkap ekspresi non-verbal, seperti ekspresi wajah dan gerakan tubuh pembicara. Tahap kedua adalah processing, yaitu pendengar mengingat komentarkomentar yang disampaikan oleh pembicara, kemudian menyampaikan klarifikasi dengan bertanya pada hal yang perlu diklarifikasi. Pendengar menghubungkan berbagai hal sehingga mampu memaknai pesan secara utuh. Pendengar melakukan paraphrasing, yaitu pendengar menyampaikan kembali informasi yang telah diterima kepada pembicara dan memastikan bahwa informasi itu telah dimengerti. Pendengar juga melakukan evaluasi pada isi pembicaraan dan menerima, merasakan pemikiran serta ide- ide pembicara. Pendengar mengindikasikan benar-benar mendengarkan pembicara. Tahap terakhir adalah responding, yaitu pendengar memberikan respons secara verbal maupun non verbal terhadap pembicara, misalnya anggukan kepala, dan sebagainya sebagai indikasi bahwa pendengar memberikan perhatian aktif terhadap pembicara.

Pelatihan active empathic listening skill ini diberikan pada guru PAUD agar guru dapat memahami minat dan kebutuhan anak, serta agar dapat berempati terhadap anak. Guru dapat mendorong anak untuk melakukan eksplorasi terhadap lingkungan sekitarnya, menjawab rasa ingin tahu anak, sehingga anak akan menyukai proses belajar sampai mereka dewasa nantinya (Berns, 2013). Bodie (2011) menyatakan, bila seseorang melakukan active empathic listening, maka dapat memberikan manfaat pada peningkatan kualitas emosinya, karena dapat mengasah kemampuan untuk mendengarkan dan memahami orang yang sedang berbicara. Manfaat lainnya yang disebutkan oleh Bodie (2011) adalah bahwa praktek active empathic listening dapat meningkatkan hubungan positif dengan orang lain, dalam hal ini hubungan guru dan anak di PAUD. Oleh karena itu, penelitian ini ingin mengetahui apakah ketrampilan active empathic listening guru dapat ditingkatkan melalui pelatihan, karena guru perlu mampu mendengarkan anak secara aktif dan empati. Guru mengikuti pelatihan ini untuk meningkatkan keterampilan active empathic listening dalam rangka meningkatkan closeness hubungan guru dan anak di PAUD. 


\section{METODE PENELITIAN}

\section{Rancangan Penelitian}

Penelitian ini merupakan experimental design, yaitu quasi eksperimental, dengan menggunakan desain penelitian one group pretest-posttest design, yaitu menggunakan satu kelompok subjek penelitian sebagai kelompok eksperimental tanpa adanya kelompok kontrol (Mertens, 2014).

\section{Subjek Penelitian}

Subjek penelitian adalah empat guru PAUD di Jakarta untuk dilihat closeness hubungan masing-masing guru dengan lima anak. Subjek pada penelitian ini adalah guru anak usia dini yang memiliki tingkat pendidikan minimal D3 dan sudah mengajar selama dua tahun. Peneliti beranggapan bahwa subjek perlu memiliki pengalaman mengajar minimal dua tahun dengan asumsi bahwa guru telah memiliki pengalaman dasar berhubungan dengan anak. Demirkaya dan Bakkaloglu (2015) menyebutkan bahwa pengalaman guru dalam mengajar berpengaruh terhadap hubungan guru dengan anak. Hal ini dimungkinkan karena dengan berjalannya waktu, pemahaman guru terhadap anak dan karakteristiknya juga meningkat karena semakin banyaknya pengalaman guru dalam berinteraksi dengan anak.

\section{Metode Pengumpulan Data}

Subjek diberikan pretest sebelum dilaksanakan intervensi yang berupa pelatihan, kemudian dilaksanakan pelatihan selama sekitar 12 jam dalam 2 hari. Posttest 1 diberikan kepada subjek dua minggu setelah pelatihan, dan post test 2 diberikan satu minggu setelah posttest 1 . Pretest dan post test yang diberikan kepada subjek adalah AELS dan STRS yang telah diadaptasi, bertujuan untuk mengetahui ada tidaknya perubahan keterampilan active empathic listening guru maupun perubahan hubungan guru dan anak setelah subjek mempraktikkan hasil pelatihan.

Observasi berdasarkan behavioral checklist form juga dilakukan pada saat pengambilan data di posttest pertama dan posttest kedua selama satu hari KBM. Observasi ini dilakukan bertujuan untuk melihat konsistensi antara perilaku yang tampak dengan hasil kuesioner (STRS dan AELS) yang diberikan kepada subjek.

\section{Student-Teacher Relationship Scale (STRS)}

Pengukuran hubungan guru anak dilakukan dengan menggunakan StudentTeacher Relationship Scale (STRS) yang disusun oleh Pianta (2001). Alat ukur ini disusun berdasarkan tiga dimensi hubungan guru dan anak oleh Pianta (2001). Skala ini merupakan skala Likert, diisi dengan memberi lingkaran pada kolom angka yang sudah disediakan, dari angka 1 sampai 5, dengan rentang 1 (sangat tidak sesuai) sampai 5 (sangat sesuai). Skor minimal yang kemungkinan diperoleh subjek pada dimensi closeness adalah 10 dan skor maksimalnya adalah 50 . Skor minimal yang kemungkinan diperoleh subjek pada dimensi conflict adalah 9 dan skor maksimalnya adalah 45 . Skor minimal yang kemungkinan diperoleh subjek pada dimensi dependency adalah 5 dan skor maksimalnya adalah 25. Skala STRS terdiri dari 28 item, yang terbagi 3 dimensi hubungan guru-anak, yaitu: Closeness (item $\left.1,3,4^{*}, 5,7,9,12,14,23,24\right)$, Conflict (item $\left.2,11,15,17,18^{*}, 19,20,21,22\right)$, Dependency (item $6,8,10,13,16$ ). Item yang bertanda bintang $\left(^{*}\right)$ adalah item unfavourable sehingga penskorannya harus dibalik. 
Semakin tinggi skor STRS pada tiap dimensinya (dimensi closeness, conflict, dan dependency), maka semakin tinggi pula dimensi tersebut. Dalam penelitian ini, peneliti memfokuskan pada dimensi closeness. Jadi, semakin tinggi skor closeness pada hasil STRS Subjek, menunjukkan semakin tinggi pula tingkat closeness hubungan guru dan anak.

Hasil uji coba instrumen STRS kepada 37 orang guru didapatkan koefisien reabilitas cronbach's alpha sebesar 0,856. Uji validitas menggunakan teknik statistic corrected item-total correlation, terdapat 4 item yang tidak valid yaitu item nomor 13 , 21, 24 dan 25. Berdasarkan hasil tersebut, maka pada lembar kuesioner guru item nomor 13, 21, 24 dan 25 dihilangkan.

\section{Behavioral checklist form}

Alat ukur kualitatif menggunakan Behavioral checklist form disusun berdasarkan indikator perilaku pada dimensi closeness dalam STRS yang dibuat berdasarkan teori Pianta (2001). Form ini digunakan sebagai alat bantu observasi yang bertujuan sebagai pengecekan kesesuaian antara hasil pada dimensi closeness STRS dengan perilaku yang muncul antara Subjek dan anak ketika berinteraksi di PAUD. Form ini diisi dengan memberi tanda checklist $(\sqrt{ })$ pada kolom pilihan skor angka. Berikut ini adalah kisi-kisi lembar observasi hubungan guru-anak berdasarkan STRS yang mencakup kriteria, indikator, dan skor.

Tabel 1. Kisi-Kisi Lembar Observasi Hubungan Guru-Anak

\begin{tabular}{lll}
\hline Dimensi STRS & \multicolumn{1}{c}{ Indikator Perilaku } & Skor \\
& \multicolumn{1}{c}{ Hubungan Guru-Anak } & \\
\hline Closeness & + Adanya komunikasi terbuka & 0 = Tidak terlihat \\
& + Adanya afeksi dan kehangatan & $1=$ Terlihat namun jarang/ tidak \\
& + Adanya perhatian & konsisten. \\
& + Guru berperan sebagai sumber & 2 = Sering terlihat $/$ konsisten \\
& dukungan bagi anak & \\
\hline
\end{tabular}

Setiap pernyataan di atas diberikan 3 skala rating, mulai dari 0 sampai dengan 2 . Apabila indikator tidak tampak sama sekali maka diberi skor 0. Apabila indikator sering muncul (muncul lebih dari 3 kali dalam satu hari pertemuan), akan diberi skor 2. Apabila indikator terlihat namun jarang (muncul sebanyak 1 sampai 3 kali dalam satu hari pertemuan), muncul/ tidak konsisten akan diberi skor 1.

Peneliti melakukan uji coba terhadap behavioral checklist form sebelum digunakan. Hal ini dilakukan untuk mengetahui sejauh mana reliabilitas dari alat ukur yang telah disusun. Melalui kegiatan uji coba alat ukur ini akan diketahui item pertanyaan yang sebaiknya harus diubah, dikurangi ataupun ditambah. Reliabilitas yang digunakan adalah interrater reliability. Proses pengujian reliabilitas ini dilakukan dengan meninjau rekaman singkat interaksi guru dan anak. Observasi dilakukan oleh 2 observer yaitu peneliti sendiri dan seorang sarjana psikologi yang sudah beberapa kali menjadi pemateri pelatihan untuk guru. Untuk mengetahui alat ukur yang digunakan reliabel atau tidak, hasil observasi antar observer dihitung 
berdasarkan rumus yang disampaikan oleh Shaugnessy, Zechmeister, Zechmeister (2000), di mana jumlah item yang sesuai antar observer dibagi jumlah seluruh item kemudian dikalikan 100\%. Apabila hasil observasi yang dihitung dengan rumus tersebut menunjukkan 85\% kesesuaian hasil observasi antar observer, maka alat ukur tersebut dapat dikatakan reliabel. Apabila kurang dari 85\%, maka alat ukur tersebut tidak dapat dikatakan reliabel (Shaugnessy, Zechmeister \& Zechmeister, 2000).

Setelah observer 1 dan observer 2 memberikan skor pada lembar behavior checklist, kedua observer menghitung hasil observasi berdasarkan rumus tersebut. Hasilnya menunjukkan kesesuaian antara observer 1 dan observer 2 sebesar 90\%, sehingga behavioral checklist tersebut dapat dikatakan reliabel karena melebihi batas minimal $85 \%$.

\section{Active Empathic Listening Scale (AELS)}

Pengukuran active empathic listening dilakukan dengan menggunakan adaptasi dari Active Empathic Listening Scale (AELS) yang disusun oleh Bodie (2011). Alat ukur ini disusun berdasarkan tiga proses keterampilan mendengarkan secara aktif dan empatik oleh Bodie (2011), yaitu sensing, processing, dan responding. Skala ini merupakan skala Likert, diisi dengan memberi tanda lingkaran pada kolom angka yang sudah disediakan, dari angka 1 sampai 7 dengan rentang 1 (tidak pernah atau hampir tidak pernah) sampai 7 (selalu atau hampir selalu). Ada 11 item yang terbagi 3 tahapan dalam alat ukur ini, yaitu sensing ( 4 item) pada nomor: 1, 2, 3, 4, kemudian processing (3 item) nomor: 5, 6, 7 dan responding (4 item) nomor: $8,9,10,11$. Skor minimal yang kemungkinan diperoleh subjek adalah 11 dan skor maksimalnya adalah 77.

Peneliti melakukan uji reliabilitas dan uji validitas untuk AELS kepada 57 orang guru PAUD. Hasil uji coba alat ukur didapatkan koefisien reabilitas cronbach's alpha sebesar 0,789. Uji validitas yang menggunakan tehnik statistic corrected item-total correlation tidak terdapat item yang tidak valid.

\section{Prosedur Intervensi}

Pelatihan active empathic listening skill ini diberikan kepada guru PAUD dengan tujuan, merujuk kepada Yuwono, Suhariadi, Handoyo, Fajriarthi, Muhamad, dan Septarini, (2005), agar individu dapat menguasai pengetahuan, keterampilan, dan perilaku yang dilatihkan dalam program pelatihan sehingga dapat diaplikasikan dalam kegiatan sehari-hari mereka. Materi dalam pelatihan bertujuan membantu partisipan untuk meningkatkan keterampilan pada tugas tertentu, khususnya keterampilan mendengarkan guru secara aktif dan empatik dalam rangka menjalin kedekatan hubungan guru dan anak di PAUD. Selanjutnya, pelatihan dapat dilaksanakan dengan baik dan hasilnya dapat optimal jika menerapkan suatu metode atau teknik tertentu dalam prosesnya. Oleh karena itu peneliti menggunakan beberapa teknik saat pelatihan active empathic listening skill berlangsung (Cannata, Garriner, Taylor \& Arvalo, 2006). Pertama: ceramah. Teknik ini dilakukan dengan komunikasi satu arah. Fasilitator berbicara kepada partisipan, kemudian partisipan hanya mendengarkan dan mencoba memahami penjelasan fasilitator. Fasilitator intervensi menggunakan alat bantu visual seperti projector, modul, gambar, dan video untuk membantu 
penjelasan materi. Kedua: brainstorming. Brainstorming merupakan suatu cara untuk mengumpulkan berbagai ide dan teknik yang efektif dari partisipan agar partisipan berpartisipasi dan berkontribusi. Brainstorming dilakukan khususnya pada saat awal sesi pelatihan agar semua fokus kepada apa yang ingin dibahas dalam sesi tersebut. Saat melakukan brainstorming partisipan diharapkan dapat menerima ide/opini antar-partisipan, dan tidak saling mengkritik ide antar-partisipan. Ketiga: Diskusi Diskusi bertujuan untuk menggali ide dan opini partisipan. Diskusi merupakan cara interaksi dua arah antara fasilitator dengan partisipan atau sesama partisipan. Para partisipan dapat saling memperdebatkan opini atau mengkritik poin tertentu dalam diskusi. Diskusi sangat efektif dilakukan setelah sesi pelatihan sebagai bahan refleksi diri. Keempat: Role Play. Role play merupakan dramatisasi informal atau memeragakan satu peran dalam drama yang bisa dilakukan oleh partisipan pelatihan. Role play dapat dilakukan oleh dua orang atau lebih dalam satu kelompok. Role play memiliki tema tertentu yang berhubungan dengan pelatihan. Partisipan berdiskusi mengenai pengalaman saat melakukan role play setelah melakukan role play. Partisipan diberikan pretest sebelum dilaksanakan intervensi yang berupa pelatihan, kemudian dilaksanakan pelatihan selama sekitar 12 jam dalam 2 hari.

\section{Teknik Analisis Data}

Data kuantitatif dalam penelitian ini dianalisis dengan uji Wilcoxon Signed Rank dari SPSS.

\section{HASIL PENELITIAN}

\section{Hasil Analisis Skor Active Empathic Listening Skill}

Peneliti melakukan uji non parametrik Wilcoxon Signed Rank dari data kuesioner yang diisi oleh guru untuk melihat signifikansi dari perubahan active empathic listening skill tersebut yang dapat dilihat dari tabel berikut ini.

Tabel 2. Hasil Analisis Data Active Empathic Listenaning Skill dengan Wilcoxon

\begin{tabular}{ccc}
\hline & Post 1 - Pretest & Post 2- Post 1 \\
\hline $\mathrm{Z}$ & $-1.826^{\mathrm{b}}$ & $-1.342^{\mathrm{b}}$ \\
Asymp. Sig. (1-tailed) & .034 & .09 \\
\hline
\end{tabular}

Tabel 2 di atas menunjukkan adanya perubahan signifikan pada kenaikan tingkat antara AELS prates dan pascates $1 \mathrm{z}$ $=-1.826, \mathrm{p}=0.34<0,05$ ), namun tidak terdapat peningkatan yang signifikan antara pascates 1 dan pascates $2(\mathrm{z}=-1.342, \mathrm{p}=$ $0.090>0,05)$. Pengolahan data kuantitatif juga dilakukan dengan membandingkan skor rata-rata subjek pada saat prates, pascates 1, dan pascates 2. Berikut merupakan gambar perubahan skor ratarata keterampilan active empathic listening guru yang diperoleh menggunakan alat ukur AELS. 


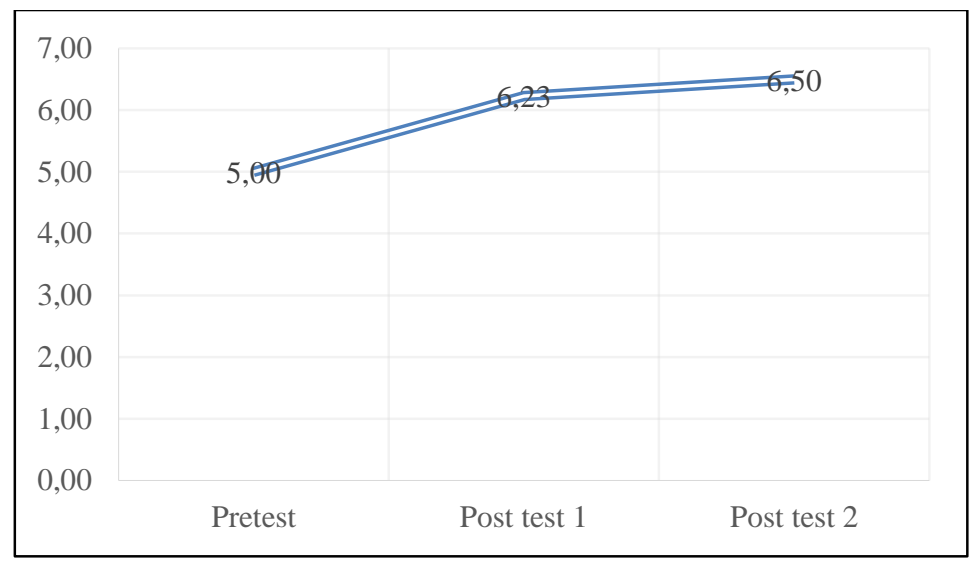

Gambar 2 Perubahan Skor Rata-rata Active Empathic Listening Skill

Gambar di atas menunjukkan adanya peningkatan skor rata-rata active empathic listening skill guru sebelum mengikuti pelatihan (pretest), dibandingkan dengan setelah mengikuti pelatihan (post test 1 dan post test 2). Dalam grafik tersebut terlihat bahwa setelah dua minggu dari diadakannya pelatihan, active empathic listening skill guru pada post test 1 dan bertambah meningkat pada post test 2 pada satu minggu kemudian.

\section{Hasil Analisis Skor Closeness Hubungan Guru dan Anak}

Peneliti melakukan uji non parametrik Wilcoxon Signed Rank dari data kuesioner yang diisi oleh guru untuk melihat signifikansi dari perubahan tersebut yang dapat dilihat dari tabel berikut.

Tabel 3 Hasil Analisis Data Closenenss dengan Wilcoxon

\begin{tabular}{lrr}
\hline & Post test1 - Pretest & Post test 2 - Post test 1 \\
\hline $\mathrm{Z}$ & $-3.560^{\mathrm{a}}$ & $-3.220^{\mathrm{a}}$ \\
Asymp. Sig. (2-tailed) & .000 & .001 \\
\hline
\end{tabular}

Dari tabel menunjukkan adanya perubahan sangat signifikan pada kenaikan tingkat closeness hubungan guru dan anak antara pre test dan post test $1(\mathrm{z}=-3.560, \mathrm{p}$ $=0.000<0,01)$. Perbandingan tingkat post test 1 dengan post test 2 juga menunjukkan adanya perubahan signifikan pada kenaikan tingkat closeness hubungan guru dan anak $(\mathrm{z}$ $=-3.220, \mathrm{p}=0.001<0,05)$. Tabel tersebut menunjukkan bahwa intervensi pelatihan active empathic listening skill pada subjek telah meningkatkan closeness hubungan guru dan anak secara signifikan.

Pengolahan data kuantitatif dilakukan dengan membandingkan skor rata-rata subjek pada saat pretest, post test 1 dan post test 2. Berikut merupakan gambar perubahan skor rata-rata hubungan guru 
dan anak yang diperoleh menggunakan alat

ukur STRS.

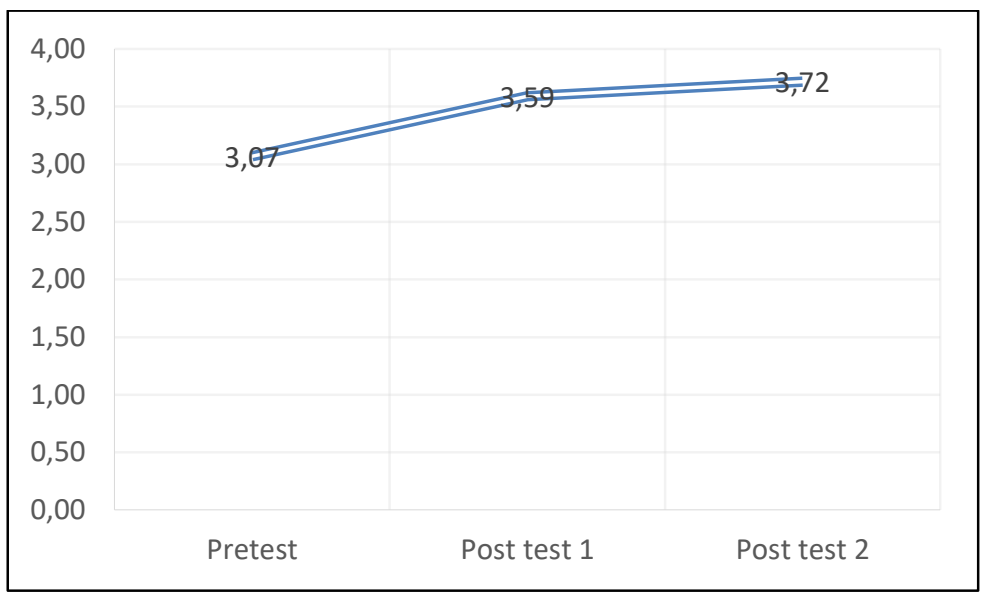

Gambar 3 Perubahan Skor Rata-rata Closeness Hubungan Guru dan Anak

Gambar tersebut menunjukkan adanya peningkatan skor rata-rata subjek, yaitu persepsi subjek terhadap hubungan guru dan anak sebelum mengikuti pelatihan (pretest), dibandingkan dengan setelah mengikuti pelatihan (post test 1 dan post test 2). Dalam grafik tersebut terlihat bahwa setelah 2 minggu dari diadakannya pelatihan, closeness hubungan guru dan anak meningkat pada post test 1 dan bertambah meningkat pada post test 2 pada 1 minggu kemudian.

\section{Hasil dan Analisis Data Behavioral Checklist}

Data dari skor Behavioral Checklist yang merupakan hasil dari observasi langsung peneliti ketika guru berinteraksi dengan anak-anak dan dikonfirmasi dari hasil rekaman.

Tabel 4. Skor Rata-rata Behavioral Checklist Hubungan Guru-Anak

\begin{tabular}{ccccccc}
\hline Dimensi & & $\mathrm{A}$ & $\mathrm{B}$ & $\mathrm{C}$ & $\mathrm{D}$ & Mean \\
\hline \multirow{2}{*}{ Closeness } & Post Test 1 & 1.44 & 1.27 & 1.38 & 1.42 & 1.41 \\
& Post Test 2 & 1.53 & 1.56 & 1.56 & 1.73 & 1.61 \\
\hline
\end{tabular}

Dari tabel di atas menunjukkan bahwa tingkat closeness guru dengan lima orang anak terdapat peningkatan, terlihat dari meningkatnya skor rata-rata closeness pada post test 1 sebesar 1.4 menjadi 1.61 pada post test 2 dari skala 0-2. Berikut ini merupakan norma skor behavioral checklist hubungan guru-anak untuk mengetahui level tinggi rendahnya. 
Tabel 5 . Norma Skor Behavioral Checklist Hubungan Guru-Anak

\begin{tabular}{ccc}
\hline Skor terendah & Skor tertinggi & Keterangan \\
\hline 0 & 0.66 & Rendah \\
0.67 & 1.33 & Sedang \\
1.34 & 2 & Tinggi \\
\hline
\end{tabular}

Berdasarkan tabel norma skor behavioral checklist di atas, diketahui bahwa secara umum (rata-rata), closeness hubungan guru dan anak yang awalnya dalam kategori sedang pada post test 1 , terjadi peningkatan pada post test 2 dengan kategori tinggi.

\section{PEMBAHASAN}

Hasil penelitian menunjukkan adanya peningkatan closeness yang signifikan dalam hubungan guru dan anak setelah guru mengikuti pelatihan active empathic listening skill dan mempraktekkannya. Hal ini sesuai dengan penelitian Bodie (2011) yang menyatakan bahwa bila seseorang mempraktekkan active empathic listening maka dapat memberikan manfaat pada peningkatan kualitas emosi. Hal ini disebabkan orang tersebut dapat mengasah kemampuan untuk mendengarkan dan memahami orang yang sedang berbicara, sehingga dapat meningkatkan hubungan positif dengan orang lain, dalam hal ini hubungan guru dan anak di PAUD.

Guru sebagai subjek penelitian, melakukan berbagai simulasi dalam tahapan active empathic listening skill yaitu sensing, processing, dan responding dalam pelatihan tersebut Guru merasakan kenyamanan dalam posisi sebagai pihak yang mendapatkan respon dari lawan bicara yang mempraktekkan active empathic listening skill. Guru melakukan empati bila berada di posisi anak didiknya, sehingga termotivasi untuk menerapkan active empathic listening skill ketika berinteraksi dengan anak, membuat anak merasa nyaman bersama guru dan menjadi dekat hubungannya dengan guru. Hasil penelitian ini sejalan dengan penelitian yang dilakukan oleh Vickery, Keaton dan Bodie (2015) yang menunjukkan bahwa keterampilan mendengarkan yang dilakukan dengan aktif dan empatik juga menunjukkan tingkat keberhasilan yang lebih tinggi dalam menjalin hubungan interaksi dengan orang lain.

Hasil penelitian ini juga sesuai dengan hasil penelitian Pianta (2001) yang menunjukkan bahwa guru yang memiliki closeness dengan anak didiknya menunjukkan memiliki kepekaan terhadap anak. Kepekaan mewakili adanya empati yang dilakukan oleh guru dalam penelitian tersebut. Empati merupakan kemampuan untuk memposisikan diri pada posisi orang lain dan merasakan apa yang dirasakan oleh orang lain (Papalia, Old \& Feldman, 2001). Ketika guru menerapkan keterampilan mendengarkan yang aktif dan penuh empati, ternyata memberikan pengaruh terhadap peningkatan closeness guru dan anak di sekolah. Hal ini terlihat dari hasil analisa data kuesioner STRS dan AELS yang diisi oleh guru yang menunjukkan bahwa guru PAUD sebagai subjek telah menerapkan empati saat mempraktekkan active 
empathic listening skill ketika berinteraksi dengan anak

Hasil pengamatan berdasarkan lembar behavioral checklist mengkonfirmasi adanya perubahan yang signifikan yaitu terdapat peningkatan closeness hubungan guru dan anak setelah intervensi dilakukan. Tiga dari empat subjek adalah guru yang memiliki usia, dan pengalaman antara 5 sampai 15 tahun dalam mengajar di PAUD, sehingga mereka berkesempatan lebih tinggi mempraktekkan kemampuan komunikasi aktif dan empatik dalam rangka lebih meningkatkan closeness dengan anak. Hal ini sesuai dengan penelitian yang dilakukan oleh Kourmousi, Amanaki, Tzavara dan Koutras (2017) dan didukung oleh penelitian oleh Demirkaya dan Bakkaloglu (2015) yang menunjukkan bahwa pengalaman guru dalam mengajar berpengaruh terhadap kedekatan hubungan guru dengan anak. Guru yang memiliki usia dan pengalaman mengajar yang semakin tinggi juga cenderung memiliki closeness hubungan dengan guru dan anak.

Hasil wawancara terhadap semua guru memperlihatkan bahwa secara umum, anak-anak cenderung menjadi lebih kooperatif setelah proses pelatihan. Hal ini terlihat sebagai contoh ketika kegiatan untuk pentas seni anak-anak semangat berlatih dan cenderung lebih mudah diarahkan. Hasil penelitian ini sejalan dengan hasil penelitian yang dilakukan oleh Nurmi (2012) yang menunjukkan bahwa peningkatan closeness dalam hubungan guru dan anak menyebabkan adanya peningkatan motivasi dan keterlibatan anak terhadap sekolah.

Keterbatasan dari penelitian ini yaitu bahwa dari alat ukur STRS hanya dapat melihat dimensi hubungan antara guru dan anak dari sudut pandang guru saja, sehingga perlu juga diperoleh persepsi hubungan guru dengan anak dari sudut pandang anak.

\section{SIMPULAN DAN SARAN}

\section{Simpulan}

Hasil penelitian menunjukkan terdapat peningkatan closeness hubungan guru dan anak di PAUD melalui pelatihan active empathic listening skill. Hal ini terbukti dari adanya peningkatan yang signifikan pada skor closeness hubungan guru dan anak dan skor active empathic listening skill sebelum dan sesudah guru mendapatkan pelatihan. Dengan demikian, dapat dikatakan bahwa peningkatan active empathic listening skill guru berpengaruh terhadap peningkatan closeness dalam hubungan guru dan anak.

Hasil observasi menggunakan lembar behavioral checklist yang disusun berdasarkan STRS memperlihatkan adanya perubahan hubungan guru dengan anak berdasarkan observasi terhadap situasi interaksi guru dan anak, baik saat KBM maupun di luar KBM selama anak di sekolah.

\section{Saran}

Sebagai bahan pertimbangan untuk penelitian berikutnya beberapa saran yang dapat dipaparkan adalah sebagai berikut. Pertama: Keterampilan active empathic listening bukan keterampilan instan, perlu dilatih dan dilakukan terus menerus secara sistemik, maka perlu ada sesi coaching beberapa hari setelah training dan kontrol program untuk mengingatkan dan menjaga konsistensi untuk mendapatkan hasil yang lebih baik lagi. Kedua: Pengukuran program intervensi disarankan tidak berhenti hanya pada persepsi guru saja, namun juga dari persepsi anak. Lebih baik lagi bila dapat melihat dampak positif terhadap perilaku 
Pelatihan Ketrampilan Mendengarkan Empatik Aktif untuk Meningkatkan Kedekatan Guru dan Anak

anak. Ketiga: Pada penelitian ini, variabell karakter anak atau permasalahan psikologis pada anak tidak terukur oleh STRS. Oleh karena itu, perlu adanya penelitian lanjutan untuk melihat kontribusi dari hal-hal tersebut yang mungkin mempengaruhi perubahan hubungan guru dan anak. 


\section{DAFTAR PUSTAKA}

Allison, C., Baron-Cohen, S., Wheelwright, S. J., Stone, M. H., dan Muncer, S. J. (2011). Psychometric analysis of the Empathy Quotient (EQ). Personality and Individual Differences, 51, 829-835.

Ashokan, V.. (2014). Thematic approach for effective communication in ECCE. International Journal of Education and Psychological Research. 3 (3).

Berns, R., M. (2013). Child, family, school, community: socialization and support. Ninth edition. Wadsworth: Cengage Learning.

Birch, S. H. \& Ladd, G. W. (1997). The teacher-child relationship and children's early school adjustment. Journal of School Psychology, 35(1), 61-79.

Bodie, G.D. (2011). The Active-Empathic Listening Scale (AELS): Conceptualization and evidence of validity within the interpersonal domain. Communication Quarterly, 59, 277-295. Doi:10.1080/01463373. 2011.583495

Bodie, G. D., Vickery, A. J., Cannava, K., dan Jones S. M. (2013). The role of "Active Listening" in informal helping conversations: Impact on perceptions of listener helpfulness, sensitivity, and supportiveness and discloser emotional improvement. Western Journal of Communication, 79(2), 151173, DOI: $10.1080 / 10570314$. 2014.943429

Cannata, A. \& Garringer, M. (2006), Preparing participants for mentoring. USA: The Mentoring Resource Centre.

Commodari, E. (2013). Preschool teacher attachment, school readiness and risk of learning difficulties. Early Childhood Research Quarterly, 28, 123 - 133.
Demirkaya, P. N. dan Bakkaloglu, H. (2015). Examining the student-teacher relationships of children both with and without special needs in preschool classrooms. Educational Sciences: Theory and Practice. 15 (1), 159-175. DOI 10.12738/estp. 2015.1.2590

Drollinger, T., Comer, L. B., \& Warrington, P. T. (2006). Development and validation of the Active Empathetic Listening Scale. Psychology and Marketing, 23, 161-180. Doi:10.1002=Mar.20105

Duta, N., Panisoara, G., \& Panisoara, I. O. (2015). The Effective communication in teaching: Diagnostic study regarding the academic learning motivation to students. Procedia Social and Behavioral Sciences, 186, 1007-1012 https://doi.org/ 10.1016/j.sbspro.2015.04.064

Fauzi, A. I. K. (2011). Mengelola pelatihan partisipatif. Bandung: Alfabeta

Gearhart, C. C., dan Bodie, G. D. (2011). Active-empathic listening as a general social skill: Evidence from bivariate and canonical correlations. Communication Reports, 24, 86-98. Doi:10.1080=08934215.2011.610731

Koomen, H.M.Y., Verschueren, K., van Schooten, E., Jak, S., Pianta, R.C., et al. (2012). Validating the student-teacher relationship scale: Testing factor structure and measurement invariance across child gender and age in a Dutch sample. Journal of Social Psychology, 5(2), 215-234.

Kourmousi N., Amanaki E., Tzavara C., \& Koutras, V. (2017). Active Listening Attitude Scale (ALAS): Reliability and validity in a nationwide sample of Greek educators. Social Sciences. doi:10.3390/socsci6010028 
Lloyd, K.J., Boer, D., \& Voelpel, S.C. (2015). From listening to leading: Toward an understanding of supervisor listening within the framework of LeaderMember Exchange Theory. International Journal of Business Communication, 54(4), 431-451. https://doi.org/10.1177/232948841 5572778

Lynch, S. A. \& Warner, L. (2013). Preschool: How adults foster young children's intellectual development. YC Young Children, 68(2), 86-91.

Menteri Pendidikan dan Kebudayaan Republik Indonesia. (2014a). Permendikbud Nomor 137 Tahun 2014 Tentang Standar Nasional Pendidikan Anak Usia Dini. Diunduh 10 Oktober 2018, dari https://luk.staff.ugm.ac.id/atur/bsnp /Permendikbud137-2014Standar NasionalPAUD.pdf

Menteri Pendidikan dan Kebudayaan Republik Indonesia. (2014b). Permendikbud No. 146 Tahun 2014 Tentang Kurikulum 2013 Pendidikan Anak Usia Dini. Diunduh 10 Oktober 2018, dari http://paud.kemdikbud. go.id/wp-content/uploads/2016/04/ Permendikbud-146-Tahun-2014.pdf.

Mertens, D. M. (2014). Research and evaluation in education and psychology, 4th Edition. Thousand Oaks: Sage Publication Inc.

Myers, S. \& Morris, A. (2009). Examining associations between effortful control and teacher-child relationships in relation to head start children's socio emotional Adjustment. Early Education and Development, 20(5), 756-774. Doi:10.1080/10409280 802571244

Nurmi, J.E. (2012). Students' Characteristics and teacher-child relationships in instruction: A meta-analysis. Educational Research Review , 7, 177197. http://dx.doi.org/ 10.1016/ j.edurev.2012.03.001
Papalia, D., Old, S., dan Feldman, R. (2001). Perkembangan Manusia. Jakarta: Salemba Humanika.

Peck N. F., Maude S. P. and Brotherson M. J. (2015). Understanding preschool teachers' perspectives on empathy: A qualitative inquiry. Early Childhood Education Journal, 43, 169-179.

Pence, M. E. dan Vickery, A. J. (2012). The Roles of personality and trait emotional intelligence in the activeempathic listening process: Evidence from correlational and regression analyses. International Journal of Listening. https://doi.org/10.1080/ $\underline{10904018.2012 .712810}$

Pianta, R. C. (2001). Student-teacher relationship scale: professional manual. Lutz: Psychological Assessment Resources.

Pianta, R. C., Downer, Jason., \& Hamre, B. (2016). Quality in early education classrooms: Definitions, gaps, and systems. The Future of Children, 26(2),119-137

Rahiem, M. D. H., Abdullah, M. N. S. dan Rahim, H. (2012). School culture and the moral development of children. International Proceedings of Economics Development and Research. DOI: 10.7763/IPEDR. 2012. V56. 23

Rudasill, K. M., Reio, T. G. R., Stipanovic, N., \& Taylor, J. E. (2010). A longitudinal study of student-teacher relationship quality, difficult temperament, and risky behavior from childhood to early adolescence. Educational Psychology Papers and Publications. 120. University of Nebraska - Lincoln. http://digitalcommons.unl.edu/edpsy chpapers $/ 120$

Santrock, J, W. (2011). Educational psychology, $5^{\text {th }}$ ed. New York: McGrawHill. 
Shaugnessy, J., Zechmeister, E., \& Zechmeister, J. (2000). Research methods in psychology. New York: McGraw-Hill.

Slavin, R. E. (2011). Psikologi pendidikan. Edisi ke sembilan. Jakarta: Penerbit Indeks.

Tim Pengembang Ilmu Pendidikan FIP UPI. (2007). Ilmu dan aplikasi pendidikan, Bagian 4 Pendidikan Lintas Bidang. Bandung: PT. Imtima.

Vickery, A. J., Keaton, S. A., dan Bodie G. D. (2015). Intrapersonal communication and listening goals: An examination of attributes and functions of imagined interactions and Active-Empathic Listening Behaviors. Southern Communication Journal, 80(1), 20-38.
Weger, H., Castle Bell, G., Minei, E. M., \& Robinson, M. C. (2014). The relative effectiveness of active listening in initial interactions. International Journal of Listening, 28, 13-31. http://dx.doi.org/10.10 80/10904018.2013.813234

Yuwono, I., Suhariadi, F., Handoyo, S., Fajriarthi, Muhammad, B.S., \& Septarini, B.G. (2005). Psikologi industri dan organisasi. Surabaya: Fakultas Psikologi Unair.

Zee, M., de Jong, P. F., Komen, H. M. Y. (2016). Teachers' self-efficacy in relation to individual students with a variety of social-emotional behaviors: e multilevel investigation. Journal of educational Psychology, 108 (7), 10131027. doi: $10.1037 /$ edu0000106 